\title{
Redes Sociais e Comportamento Sexual: para uma visão relacional da sexualidade, do risco $e$ da prevenção'
}

Social Networks and Sexual Behaviour: towards a relational approach to sexuality, risk-taking behaviour and prevention practices

\author{
Sofia Aboim \\ Pesquisadora Auxiliar do Instituto de Ciências Sociais da Univer- \\ sidade de Lisboa. \\ Endereço: Av. Professor Aníbal de Bettencourt, 9, 1600-189, Lisboa, \\ Portugal. \\ E-mail: sofia.aboimळics.ul.pt \\ I Esta pesquisa foi financiada pela Coordenação Nacional da \\ Infecção HIV/AIDS (Portugal) e realizada no Instituto de Ciências \\ Sociais da Universidade de Lisboa.
}

\section{Resumo}

Com base num inquérito representativo da população portuguesa entre 18 e 65 anos, realizado em 2007, este estudo investiga o impacto de fatores de rede social sobre os comportamentos sexuais dos indivíduos. Através da percepção normativa dos inquiridos sobre a moral sexual dos seus amigos e familiares e de indicadores relativos à caracterização da rede de confidência sexual, tais como o número, a identidade, o gênero, a idade e o comportamento dos confidentes em matéria de sexualidade e prevenção face ao risco de infecção por DSTs, obtivemos um retrato multidimensional das redes sociais dos indivíduos. A realização de análises de regressão linear e logística permitiu avaliar o impacto preditivo da rede sobre o número de parceiros sexuais, as relações sexuais ocasionais e o uso do preservativo. Os dados mostram que os fatores de rede são importantes para explicar o comportamento sexual dos indivíduos. Redes constituídas por amigos e mais liberais em termos de moral sexual tendem a influenciar o comportamento sexual, levando a um maior experimentalismo, sobretudo no caso das mulheres. Por outro lado, a homologia entre o comportamento sexual dos confidentes e o dos inquiridos é relevante para explicar o recurso ao preservativo nas relações sexuais ocasionais, especialmente no caso dos homens. Tanto numa perspectiva relacional da sexualidade como numa óptica epidemiológica, a análise das redes sociais dos indivíduos constitui um aspecto importante para a compreensão e explicação da variedade de experiências sexuais, 
mais restritas ou mais plurais, e para os riscos de infecção que daí podem advir.

Palavras-chave: Síndrome de Imunodeficiência Adquirida; Doenças Sexualmente Transmissíveis; Comportamento Sexual; Redes Sociais; Fatores de Risco.

\section{Abstract}

Based on a representative survey of the Portuguese population aged between 18 and 65, carried out in 2007 , this study investigates the impact of social networks on the sexual behaviour of individuals. Through the normative perceptions respondents have of the sexual morals of their family members and friends, as well as through a number of indicators related to the characterization of the network of sexual confidants, such as number, identity, gender, age and confidants' behaviour in terms of sexuality and risk-taking practices, we were able to draw a multidimensional portrait of the individuals' social networks. By carrying out several linear and logistic regression analyses, we were also able to evaluate the predictive power of network variables and their effect on the number of sexual partners, occasional sex and condom use. Data show that network factors are important to explain individuals' sexual behaviour. Confidence networks constituted by friends and orientated towards a more liberal sexual moral tend to allow for a greater sexual experimentalism, particularly in the case of women. On the other hand, the homology between confidants' and respondents' sexual behaviour seems relevant to explain condom use in occasional sex, especially in the case of men. Either by taking on a relational perspective or an epidemiological approach, the analysis of individuals' social networks constitutes a major feature for understanding and explaining the variety of sexual experiences and the infection risks that can be associated with sexual behaviour.

Keywords: Acquired Immunodeficiency Syndrome; Sexually Transmitted Diseases; Sexual Behaviour; Social Networks; Risk Factors. 


\section{Introdução}

Este artigo parte de uma idéia central, ao propor que os comportamentos sexuais dos indivíduos, bem como as suas percepções e estratégias de prevenção face ao risco de se infectarem por uma doença sexualmente transmissível (DST), não são independentes da forma como, ao longo da vida, estes se inserem em determinadas redes sociais. Como tem sido argumentado, essas redes de relações poderão condicionar tanto as orientações normativas dos indivíduos relativamente à moral sexual, como os seus comportamentos sexuais. Na verdade, a hipótese que associa biografias sexuais e redes sociais tem sido explorada em inúmeras pesquisas sobre comportamento sexual e risco de transmissão de DSTs, tanto nos Estados Unidos (Fowler e Christakis 2008; Smith e Christakis 2008; Heckathorn e col.,1999) e no Brasil (Barcellos e Bastos, 1996), como na Europa (Ferrand e Mounier 1993, 1998; Bajos e Marquet, 200o) ou na África (Behrman e col., 2003). Duas preocupações são importantes na maioria destes estudos ( veja especialmente:Heckathorn e col., 1999).

Por um lado, de um ponto de vista epidemiológico, as redes de relações sociais têm constituído um ponto de partida para analisar, visando prever e prevenir, eventuais riscos de disseminação de DSTs. Nesta óptica, as redes sociais são normalmente consideradas importantes por duas razões fundamentais. 0 primeiro motivo reside no fato de os parceiros sexuais tenderem a ser selecionados no interior do universo relacional do indivíduo (Laumann e col., 1994; Liljeros e col., 2003). O segundo motivo advém das funções de controlo social que podem ser atribuídas às redes sociais (Heckathorn, 1990). Com efeito, mesmo em contextos de crescente individualização das vivências da sexualidade (Bozon, 2005), o grau de conservadorismo ou de permissividade da rede social tende a exercer efeitos de pressão normativa sobre os comportamentos individuais, ora restrin- gindo ou ampliando o experimentalismo sexual, ora estimulando ou desencorajando o recurso a práticas preventivas (Heckathorn e col., 1999). ${ }^{2}$ Nesta óptica, o mais importante seria então determinar ocorrências e probabilidades de transmissão, propiciadas pelas interações entre o indivíduo e os membros da sua rede social.

Por outro lado, numa perspectiva relacional da sexualidade (Ferrand e Mounier, 1993, 1998), por exemplo, investigar as redes sociais dos indivíduos comporta implicações talvez ainda mais abrangentes.

Um primeiro aspecto importante reflete-se na abordagem dos condicionamentos normativos que emergem das relações sociais em rede, mas sem se concentrar, como a perspectiva epidemiológica, exclusivamente nas questões do risco e da transmissão de DSTs. Assim, na óptica relacional importa examinar com maior profundidade as formas de controlo social, normativas e efetivas, que os indivíduos podem exercer uns sobre os outros. Com efeito, as mudanças profundas que têm vindo a alterar o cenário da vida privada, permitindo maior liberdade aos atores sociais - nomeadamente às mulheres - $\mathrm{e}$ um controlo mais individualizado da própria sexualidade, estão na base dos processos de pluralização das biografias sexuais (Bozon, 2005). As lógicas de experimentação sexual e o elogio do prazer erótico associam-se integralmente a processos históricos de individualização social, que progressivamente substituíram a ética institucionalista orientada para a procriação por outra, mais hedonista e centrada no indivíduo (Giddens 1996; Beck e Beck-Gernsheim, 2002). Neste processo, a libertação dos constrangimentos associados à família como instituição e ao rígido controlo exercido pelo parentesco constituem parte essencial. O primado do sangue e da aliança, ao poder do qual se submetia a sexualidade, tem sido progressivamente abandonado a favor das afinidades eletivas: as do amor romântico, como nota Luhmann (1991), ${ }^{3}$ mas igualmente as da amizade

\footnotetext{
2 Nesta óptica, a influência social que os indivíduos exercem uns sobre os outros constitui um elemento central. Segundo Festinger (1954), e mais genericamente segundo a teoria da comparação social (Erickson, 1988, p. 101-102), os indivíduos adaptam-se permanentemente às circunstâncias da interacção, na medida em que procuram adequar o seu comportamento ao que pensam serem as expectativas dos outros. As interacções grupais são tanto mais importantes como determinantes do comportamento quando maior for a flexibilidade normativa associada ao comportamento em causa. Em suma, quanto menor for a regulação social da sexualidade, como sucedia tradicionalmente, maior será a importância da interacção intra-grupal.

3 A importância da relação conjugal é aliás reconhecida do ponto de vista da análise epidemiológica das redes sociais. Grande parte dos estudos tem-se centrado no que alguns autores (Smith e Christakis, 2008) intitulam os "efeitos diádicos" das relações a dois, por contraposição à tendência emergente para se estudar a rede social alargada, ou seja, os "efeitos supra-diádicos".
} 
e da livre escolha dos próximos e afins, independentemente dos laços do sangue. Uma sexualidade liberta, assim como uma vida globalmente mais livre, dependeriam, em grande medida, do corte de amarras com o parentesco e a vigilância da comunidade, imperantes nas sociedades tradicionais (Ariès, 1973; Shorter, 1995; Elias, 1993; Flandrin, 1981).

É, por conseguinte, compreensível o fato de vários estudos elegerem esta problemática enquanto objeto, procurando examinar as conexões tecidas entre ação individual e relações sociais envolventes. Nesta óptica, a principal preocupação tem sido a de verificar empiricamente de que formas as relações sociais continuam a influenciar uma esfera privada vista como secreta e individualizada. O campo da sexualidade oferece-nos exemplos recentemente pesquisados, como é o caso do trabalho de Ferrand e Mounier na França $(1993,1998)$, que estudaram o efeito das redes de pessoas próximas sobre o comportamento sexual dos indivíduos. De forma geral, também neste domínio, a hipótese sociológica mais evidente parece encontrar eco nos dados: afinal, segundo esses autores, redes de pessoas próximas mais conservadoras em matéria de sexualidade parecem favorecer a restrição da experimentação sexual, e vice-versa.

Em segundo lugar, para além dos efeitos da regulação normativa sobre os comportamentos privados, as relações sociais correspondem igualmente a feixes de trocas materiais e simbólicas existentes nas práticas quotidianas (Scott, 200o). Neste sentido, são inúmeras as pesquisas que têm vindo a refutar a tese parsoniana (Parsons e Bales, 1955) de progressivo isolamento social dos indivíduos (ver, por exemplo, Wall e col., 2001). Nos E.U.A., não obstante a influência da tese do isolamento social (ver, por exemplo, Putnam, 1995), a pesquisa sobre redes sociais tem-se desenvolvido significativamente. Os resultados obtidos na área da saúde constituem exemplo desta tendência (Levy e Pescosolido, 2002; Bell e col., 1998; Bell e col., 2002; Bajos e Marquet, 200o). Voltando à perspectiva epidemiológica, as principais conclusões apontam para a importância das redes não só enquanto meios de disseminação de doenças, mas igualmente como centro nevrálgico da prevenção. Como demonstraram Heckathorn e col., (1999), os resultados obtidos relativamente à eficá- cia de campanhas de prevenção de DSTs foram mais elevados quando dirigidos a grupos específicos, ou seja, a redes sociais de pessoas próximas entre si, do que a indivíduos isoladamente. Como referem os autores, os esforços para evitar a disseminação da infecção HIV/aids implicam a adoção de uma perspectiva de rede, que considere o impacto das relações sociais, quer para a transmissão de DSTs, quer para a difusão de conhecimentos e disposições comportamentais de prevenção.

Neste artigo, partimos, por conseguinte, de uma perspectiva relacional da sexualidade, que situa o indivíduo na sua rede de relações sociais, cujos efeitos se fazem sentir tanto ao nível do comportamento sexual, como na disseminação e prevenção de DSTs. Propomo-nos, por conseguinte, caracterizar, de modo multidimensional, as redes sociais dos indivíduos. Seguindo a linha de pesquisa proposta por Ferrand e Mounier (1993, 1998), exploramos o conceito de rede social a partir de duas dimensões centrais: a normativa e a prática. Neste contexto, utilizaremos, ao longo do texto, dois conceitos interligados. 0 primeiro, a rede normativa, referese, em concordância com a hipótese da regulação normativa do comportamento sexual, à percepção que os indivíduos inquiridos possuem da moral sexual - mais liberal ou mais conservadora - dos seus familiares e amigos. Trata-se, por conseguinte, de uma perspectiva centrada no indivíduo (uma egorede), que faz o retrato normativo da sua rede, de acordo com a sua percepção pessoal (Scott 200o). O segundo termo, a rede prática, incide, novamente seguindo o trabalho de Ferrand e Mounier (1998) sobre as relações de confidência sexual tecidas entre o indivíduo e as pessoas próximas da sua rede social (Bell e col., 1998). A focagem na confidência - o falar sobre, o partilhar intimidade e segredo - está longe, é evidente, de ser uma opção casual. Dois motivos principais subjazem a esta estratégia teorico-metodológica, que enfatiza a proximidade e a intimidade no seio da rede.

Por um lado, o próprio ato de falar sobre a sexualidade na primeira pessoa indicia uma postura reflexiva, orientada para a verbalização da intimidade e a exposição de si em face de outros, particularmente consentânea com os ideais relacionalistas imperantes na modernidade avançada (Giddens, 1996). Ora, 
um dos aspectos centrais do processo de erotização das relações, que tem marcado as últimas décadas, reside precisamente numa crescente verbalização da sexualidade, que sai cada vez mais do domínio do privado para a arena pública, hoje marcada pela discussão, médica e social, de questões e problemas pensados como sendo do foro íntimo (Sennett, 1974). A constituição de uma reflexividade pública sobre a intimidade produz novas formas de regulação da própria sexualidade, instituindo categorias que permitem compreendê-la e partilhá-la, ou seja, o que Foucault (1976) intitulou de discursos regulativos. Além disso, a verbalização da sexualidade indica, assim, uma atitude reflexiva relativamente a si próprio que importa apreender.

Por outro lado, identificar os confidentes, um a um, permite-nos obter com maior rigor a configuração da proximidade, não a do apoio ou a da sociabilidade, mas a que se constrói pela partilha da intimidade. Captar aqueles a quem se confidenciam expectativas, problemas e segredos em matéria de sexualidade, permite-nos testar a nossa hipótese com maior precisão. Com efeito, se queremos perceber até que ponto as redes sociais podem influenciar os comportamentos sexuais dos indivíduos, funcionando, como sugere Heckathorn (Heckathorn 1990; Heckathorn e col., 1999), como lugar de ancoragem e de recriação dos discursos regulativos que controlam a sexualidade e os próprios comportamentos sexuais, nada mais adequado do que incidir seletivamente sobre a rede de confidência que se mobiliza seletivamente no seio de uma rede social mais alargada.

A dupla caracterização das redes sociais, nos seus aspetos de controle normativo e de confidência sexual, permitir-nos-á, depois, estimar os efeitos produzidos pelas variáveis de rede operacionalizadas sobre o comportamento sexual e as estratégias de prevenção mobilizadas face ao risco de infecção por DSTs, nomeadamente no respeitante ao uso do preservativo em relações sexuais com parceiros ocasionais.

\section{Material e Métodos}

Os dados analisados têm como base um inquérito representativo da população entre 18 e 65 anos, residente em Portugal Continental, realizado em 2007. A amostragem é multistage-area aleatória e estratificada ao nível da freguesia (ou seja, as divisões administrativas de menor dimensão em Portugal), por referência aos dados censitários de 2001. Foram feitas 8781 tentativas de contato em domicílios selecionados aleatoriamente em cada freguesia, tendo sido aplicados apenas 3643 questionários válidos, devido ao elevado número de recusas e de situações de não-elegibilidade (tais como, idade superior a 65 anos, ileteracia, mudança de residência, etc.) verificadas durante o trabalho de campo. O questionário foi aplicado em duas versões (uma feminina e outra masculina). A alternância entre as versões seguiu um critério aleatório sistemático. Todos os participantes do estudo foram previamente contatados e concordaram em responder às duas partes constituintes do questionário na presença do inquiridor: uma de questionamento direto pelo inquiridor e outra de auto-preenchimento. A parte auto-preenchida, em que se colocavam as questões sobre comportamentos sexuais, DSTs e práticas de prevenção, foi colocada pelo inquirido num envelope lacrado, que era depois anexado ao inquérito geral. Ambos foram colocados num segundo envelope e em seguida anonimizados, com total garantia de sigilo (Cabral e col., 2008). Em conformidade com a lesgislação portuguesa sobre ética de pesquisa, este estudo foi previamente aprovado pela Coordenação Nacional para a Infecção VIH/Sida, estando integrado no seu Programa Nacional de acção para o controle da infecção.

\section{As redes sociais: normatividade, confidência $e$ sexualidade}

No inquérito operacionalizaram-se várias questões que nos permitem explorar duas dimensões-chave das redes sociais, que esperamos tenham impacto significativo sobre o comportamento sexual dos indivíduos.

Em primeiro lugar, e em concordância com o quadro teórico de que partimos, pesquisou-se a percepção que os inquiridos têm da moral sexual dos seus familiares e amigos. Recorremos, para esse efeito a uma questão que tem sido sistematicamente utilizada em pesquisas sobre sexualidade e redes, replicando o estudo de Ferrand e Mounier (1998), no 
âmbito do inquérito francês de 1992 sobre sexualidade (Bajos e col., 1998): trata-se de uma pergunta simples em que se procura aferir qual a percepção que os indivíduos possuem sobre a aceitação da infidelidade conjugal (aventuras amorosas, mesmo tendo uma relação estável) por parte das suas redes de familiares e de amigos. Em matéria de moral sexual, o tema da infidelidade tem-se mostrado particularmente certeiro, quando o objetivo é dividir as pessoas, distinguindo entre orientações mais conservadoras e mais permissivas. Assim, perguntavase muito simplesmente até que ponto o inquirido achava que seus familiares e amigos aceitariam uma "aventura amorosa mesmo no quadro de uma relação estável”. Além disso, da forma como foi colocada, a fim de aferir separadamente a percepção sobre os amigos e sobre os familiares, a questão permite observar as diferenças normativas entre ambas as redes: a de familiares e a de amigos. Com efeito, a diferenciação entre redes de familiares e redes de amigos constitui também um aspecto central da nossa análise, em consonância com o papel diferenciado destes dois grupos em termos de controle social do comportamento sexual (Shorter, 1995; Elias, 1993). Adicionalmente, de forma a medir a maior ou menor homogeneidade ou heterogeneidade normativa da rede de amigos e de familiares, foi operacionalizada uma escala com 5 possibilidades de resposta: 1) Todos eles discordam; 2) Um ou outro concorda em certas circunstâncias; 3) Alguns concordam em certas circunstâncias; 4) A maior parte concorda em certas circunstâncias; 5) Todos eles concordam em certas circunstâncias. Partia-se da hipótese de que quanto maior a homogeidade da rede (por exemplo, com todos os familiares ou amigos concordando com a infidelidade conjugal ou vice-versa), maior seria também o controle normativo da rede sentido pelo indivíduo.

Em segundo lugar, investigou-se a dimensão relacional da rede de próximos, focando as interações de confidência sobre questões de sexualidade. Para além dos aspectos normativos acima referidos, perguntava-se ainda aos inquiridos se, para além do cônjuge (à partida excluído da rede de confidentes descrita pelos indivíduos), costumavam falar sobre a vida sexual, os problemas íntimos e as aventuras amorosas com outras pessoas. Inquiria-se quantas eram essas pessoas, pedindo-se seguidamente aos entrevistados para caracterizarem as duas pessoas com quem mais freqüentemente discutem estes assuntos íntimos: pretendiamos saber quem são esses confidentes, que laços (familiares, de amizade, etc.) têm com o inquirido, qual a sua idade, sexo e escolaridade. Obteve-se, desta forma, o desenho geral do que aqui chamaremos de "rede de confidentes", bem como as principais caracteristicas sócio-demográficas de cada um dos dois confidentes identificados pelos inquiridos.

Finalmente, para além de simplesmente caracterizar as redes de confidência, procuramos ainda examinar as percepções dos inquiridos acerca do comportamento sexual dos seus confidentes, procurando aferir-se qual a percepção dos indivíduos sobre o número de parceiros dos confidentes, bem como sobre as eventuais preocupações e precauções desses confidentes sexuais face ao risco de infecção por DSTs e nomeadamente por HIV/aids. Indagavase finalmente se havia ou tinha havido alguma relação amorosa-sexual entre os inquiridos e seus confidentes.

Como sugeriram Ferrand e Mounier (1998), a percepção sobre o comportamento sexual dos confidentes, bem como o próprio fato de ter havido contato sexual entre inquiridos e confidentes, parecem ser variáveis muito relevantes para explicar o próprio comportamento dos indivíduos em matéria de sexualidade. Será que confidentes mais preocupados com a prevenção de doenças sexualmente transmissíveis são nomeados por indivíduos que com eles partilham a mesma preocupação? Existirá homologia entre os comportamentos dos inquiridos e dos seus confidentes? Até que ponto as práticas de risco possuem uma dimensão coletiva sustentada pela influência recíproca entre indivíduos de semelhante matriz comportamental? Estas são três perguntaschave para as quais tentaremos encontrar algumas respostas através dos dados disponíveis.

\section{Comportamentos sexuais e risco potencial}

Os comportamentos sexuais (ou seja, as nossas variáveis dependentes) são analisados através de um conjunto alargado de indicadores, capazes de reconstituir elementos-chave da biografia sexual dos indivíduos, atestando a maior ou menor orientação 
para lógicas experimentalistas, por oposição a lógicas restritivas da experiência sexual. Nesta óptica, importa examinar alguns indicadores importantes na aferição de potenciais riscos de transmissão de DSTs.

Os principais indicadores reportam-se ao número de parceiros sexuais. Em primeiro lugar, importa contabilizar o total de parceiros ao longo da vida. Em segundo lugar, interessa igualmente observar a última fase da biografia sexual, identificando agora os últimos dois parceiros sexuais dos inquiridos. Ao analisar os últimos parceiros optamos por isolar os inquiridos que declararam tratar-se de relações ocasionais (com ou sem conhecimento prévio entre ambos os parceiros) e, dentre estes, identificamos ainda aqueles que não usaram preservativo nas relações sexuais tidas com pelo menos um desses dois parceiros mais recentes. A problemática do risco de doenças sexualmente transmissíveis, nomeadamente de infecção pelo HIV/aids, que esteve na base deste inquérito, levou-nos a abordar desta forma as questões relativas aos parceiros, centrando a análise nas relações ocasionais. Como é óbvio, os riscos de DSTs podem igualmente advir de relações com parceiros regulares. No entanto, a escolha dos parceiros ocasionais pareceu-nos uma estratégia analítica mais adequada em face da hipótese que pretendemos testar.

\section{Modelo de análise e estratégia analítica}

No modelo de análise que operacionalizamos, a rede (tanto a normativa como a de confidência) assume o estatuto de variável intermédia, sendo considerada enquanto elemento de mediação entre os contextos sociais e os comportamentos sexuais. As atitudes face às aventuras sexuais poderão ser influenciadas por coordenadas geracionais, escolares e de gênero, bem como pela situação conjugal e profissional dos homens e mulheres entrevistados (a este respeito, veja Irvine, 1990; Mosher e col., 2005; UNAIDS, 2008). 0 mesmo sucederá, como é evidente, ao nível da rede prática de confidência. A escolha dos confidentes, dentre familiares, amigos, colegas ou outros elementos da rede social, dependerá, em boa medida, do contexto social e da fase de ciclo de vida (familiar e profissional) em que se encontram os indivíduos. No entanto, esperamos que ambas as dimensões da rede social se articulem com os comportamentos sexuais dos indivíduos, produzindo sobre estes determinados efeitos.

Procuramos, portanto, investigar a associação entre variáveis comportamentais de risco e prevenção (número de parceiros sexuais, parceiros ocasionais na última e penúltima relação sexual, uso de preservativo nas relações sexuais ocasionais) e variáveis de rede, comparando os efeitos destas últimas com o impacto gerado por coordenadas sócio-demográficas. Para isso efetuamos várias regressões lineares e logísticas, assim testando um modelo explicativo multidimensional. As variáveis independentes foram, por conseguinte, divididas em dois grupos: um primeiro grupo contemplou as coordenadas sócio-demográficas (idade, escolaridade, situação conjugal, condição perante o trabalho) e a prática religiosa; o segundo grupo de variáveis introduziu as variáveis de rede no modelo.

\section{Resultados}

\section{Caracterização das redes sociais: rede normativa e rede de confidência}

Nesta primeira secção relativa aos resultados do estudo, iremos caracterizar as variáveis de rede, começando por analisar a dimensão normativa da rede e examinar as diferenças entre a regulação exercida diferencialmente por familiares e por amigos.

Como seria expectável face às hipóteses colocadas sobre o papel regulador da família, as redes de familiares são descritas como sendo internamente muito mais conservadoras e homogêneas do que as de amigos (tabela 1). A análise de médias mostra que as diferenças na percepção de ambos as redes de relacionamento social são particularmente evidentes. 0 universo da família (média de 1,41 na escala de 1-conservador a 5-liberal) é visto de forma muito mais conservadora do que o das afinidades amicais (média de 2,16, mais próxima do pólo liberal). Esta diferença acentua-se sobretudo no caso dos homens, pois para eles as diferenças entre as duas redes parecem ser bastante mais pronunciadas. Enquanto os familiares são percebidos de forma relativamente similar por homens e por mulheres (embora pese a visão sexualmente mais moralista com que as mulheres descrevem os seus familiares), as diferenças 
Tabela I - Distribuição da proporção (\%) de pessoas segundo sexo e variáveis de rede normativa e de confidência. Adultos em Portugal, 2007

\begin{tabular}{|c|c|c|c|}
\hline & Total & Homens & Mulheres \\
\hline \multicolumn{4}{|c|}{ Percepção da aceitação da infidelidade por parte de amigos e familiares' (médias) } \\
\hline Familiares $\left(\eta^{2}=.11^{* * *}\right)$ & 1,41 & 1,50 & 1,32 \\
\hline $\operatorname{Amigos}\left(\eta^{2}=.01^{* * *}\right)$ & 2,16 & 2,53 & 1,79 \\
\hline \multicolumn{4}{|l|}{ Redes de confidência (percentagens) } \\
\hline \multicolumn{4}{|l|}{ Número de confidentes ( $\left.c c^{i i}=n . s.\right)$} \\
\hline Nenhuma pessoa & 52,4 & 54,3 & 50,6 \\
\hline I pessoa & 20,3 & 19,1 & 21,4 \\
\hline 2 pessoas & 14,4 & 13,4 & 15,4 \\
\hline 3 ou mais pessoas & 12,9 & 13,3 & 12,6 \\
\hline Total & 100,0 & 100,0 & 100,0 \\
\hline \multicolumn{4}{|l|}{ Laço com os confidentes ( $\left.\mathrm{cc}^{\mathrm{ii}}=.31^{* * *}\right)$} \\
\hline Um/a colega de trabalho & 10,0 & 10,4 & 9,7 \\
\hline Um elemento da sua família & 28,4 & 24,6 & 31,7 \\
\hline Um/a amigo/a próximo/a & 59,0 & 61,9 & 56,3 \\
\hline Outra pessoa & 2,6 & 3,1 & 2,2 \\
\hline Total & 100,0 & 100,0 & 100,0 \\
\hline \multicolumn{4}{|l|}{ Gênero $\left(c c^{\mathrm{ii}}=.51^{* * *}\right)$} \\
\hline Rede Masculina & 30,3 & 55,6 & 8,2 \\
\hline Rede Feminina & 51,7 & 20,9 & 23,5 \\
\hline Rede mista & 18,0 & 78,6 & 13,2 \\
\hline Total & 100,0 & 100,0 & 100,0 \\
\hline \multicolumn{4}{|l|}{ Perfil etário dos confidentes $\left(c c^{\mathrm{ii}}=\right.$ n.s. ) } \\
\hline Mesmo intervalo etário & 52,0 & 53,2 & 50,9 \\
\hline Confidentes mais novos que inquirido & 19,0 & 19,6 & 18,4 \\
\hline Confidentes mais velhos que inquirido & 11,4 & 10,2 & 12,5 \\
\hline Confidentes de diferentes intervalos etários & 17,6 & 17,0 & 18,1 \\
\hline Total & 100,0 & 100,0 & 100,0 \\
\hline \multicolumn{4}{|c|}{ Percepções sobre o comportamento sexual dos confidentes no último ano } \\
\hline \multicolumn{4}{|c|}{ Confidentes fazem seleção de parceiros sexuais por causa do HIV/aids? (ccii=n.s.) } \\
\hline $\operatorname{sim}$ & 66,3 & 70,5 & 62,6 \\
\hline Não & 33,7 & 29,5 & 37,4 \\
\hline Total & 100,0 & 100,0 & 100,0 \\
\hline \multicolumn{4}{|l|}{ Confidentes multi-parceiros? $\left(c^{\mathrm{ii}}=, 45^{* * *}.\right)$} \\
\hline $\operatorname{sim}$ & 30,4 & 42,4 & 19,9 \\
\hline Não & 69,6 & 57,6 & 80,1 \\
\hline Total & 100,0 & 100,0 & 100,0 \\
\hline \multicolumn{4}{|l|}{ Relações sexuais com os confidentes ( $c c^{\mathrm{ii}}=.17^{* *}$ ) } \\
\hline Teve relações sexuais & 10,3 & 15,5 & 5,8 \\
\hline Não teve & 89,7 & 84,5 & 94,2 \\
\hline Total & 100,0 & 100,0 & 100,0 \\
\hline \multicolumn{4}{|c|}{$\begin{array}{l}\text { I) Escala: I Todos eles discordam; } 2 \text { Um ou outro concorda em certas circunstâncias; } 3 \text { Alguns concordam em certas circunstâncias; } 4 \text { A maior parte concorda em cert } \\
\text { circunstâncias; } 5 \text { Todos eles concordam em certas circunstâncias. } \\
\text { ii) Coeficiente de contingência }\end{array}$} \\
\hline
\end{tabular}


de gênero evidenciam-se nos discursos sobre os amigos. A liberdade sexual masculina parece construirse, mais do que a feminina, pela inserção em redes sociais alternativas à família, ainda um reduto conservador e fiel ao ideal de relação monogâmica face ao aparente liberalismo com que são representados os amigos (Ferrand e Snijders, 1997).

Esta diferença encaixa-se em tendências documentadas de mudança histórica das relações sociais de proximidade. 0 corte de amarras com o controlo exercido pelos parentes é indissociável dos processos de individualização (Shorter, 1995; Elias, 1993). A autonomia pessoal constitui afinal uma condição sine qua non para a expressão de uma sexualidade liberta, muito mais tardia e parcialmente conquistada pelas mulheres. A eventual erosão de laços institucionalistas seria assim decisiva para a valorização das "afinidades eletivas", termo primeiramente utilizado por Goethe, no seu romance homônimo de 1809 (republicado em 2008), para se referir ao casamento por amor e à valorização do indivíduo e das suas escolhas e desejos pessoais. Neste sentido, as relações de amizade constituem igualmente um símbolo da livre escolha. Evidentemente, a família mantém-se, no presente, extremamente importante, de certa forma simbolizando o triunfo normativo da monogamia sobre o tradicional duplo padrão de gênero no que respeita à infidelidade. Os resultados similares obtidos no masculino e no feminino assim o demonstram: nem se aceita a infidelidade dos homens nem a das mulheres. A tolerância relativamente à infidelidade e, muito provavelmente, a persistência do duplo padrão de comportamento sexual, segundo o gênero, encontra agora ancoragem no universo das relações de amizade, representadas como mais tolerantes no caso dos homens do que no das mulheres. As diferenças de gênero inerentes às percepções das redes de amigos são, pois, um dado de grande importância para compreendermos as desigualdades que se mantêm, em termos normativos, entre homens e mulheres no domínio da sexualidade (sobre normas de género e sexualidade, veja Irvine, 1990).

A segunda medida das redes, como anteriormente explicitado, incide sobre a própria rede de confidência.

Começamos agora por abordar o primeiro dos in- dicadores de caracterização da rede de confidência: o número de confidentes.

Cerca de metade dos inquiridos não referem ter qualquer confidente sexual. Curiosamente, ao contrário do que sucedia no plano normativo, o "falar de sexo" parece seguir um padrão bastante similar no que respeita ao gênero. Com efeito, a especialização feminina na reflexividade exercida sobre o domínio dos afetos e da intimidade (Giddens, 1996), não incide necessariamente sobre o plano da sexualidade, enquanto campo autônomo da discursividade. No caso dos homens, a imaginada dificuldade em expor a intimidade sexual, domínio vital da masculinidade, parece afinal não impedir os homens de, tal como as mulheres, falar de sexualidade com outros. No entanto, à semelhança dos resultados franceses (Ferrand e Mounier, 1998), entre a metade da amostra que identificou confidentes sexuais, cerca de um quinto dos homens e das mulheres falam da sua vida sexual apenas com uma pessoa, 13-14\% fá-lo com duas pessoas e somente cerca de $13 \%$ diz ter três ou mais confidentes (tabela 1). Em suma, apenas uma minoria de indivíduos parece ter uma rede alargada de partilha da intimidade sexual, contrastando com uma maioria de pessoas que ou não fala do assunto com ninguém ou o faz apenas com uma pessoa.

Depois de respondida a primeira questão sobre o número total de confidentes, era pedido aos inquiridos que caracterizassem um ou dois, no máximo, dos seus confidentes, indicando qual o laço entre ambos (tabela 1).

Como seria espectável, depois de observado o maior liberalismo dos amigos em questões de normatividade sexual, estes tendem a assumir, na prática, o papel de confidentes sexuais, encontrando-se aqui em vantagem face ao segundo agrupamento identificado - os elementos da família próxima. Entre os indivíduos que identificaram pelo menos um confidente, cerca de $62 \%$ dos homens e $56 \%$ das mulheres elegem os confidentes sexuais entre as suas relações de amizade. Em contraste, notemos que apenas $24,6 \%$ dos homens e $31,7 \%$ das mulheres nomeiam familiares. Esse ligeiro pendor "familialista”, muito menos significativo, aliás, do que o observado no plano normativo, constitui a principal diferença entre homens e mulheres.

Outros dois aspectos importantes para a ca- 
racterização das redes de confidentes prendem-se com o sexo e a idade desses mesmos confidentes (tabela 1).

Começando pelo primeiro indicador, podemos observar qual o perfil das redes em termos de gênero. No total da amostra, mais de metade das redes de confidentes são constituídas por mulheres, tratando-se exclusivamente de redes femininas. Cerca de $30 \%$ são redes masculinas e apenas $18 \%$ são redes mistas, ou seja, incluem simultaneamente homens e mulheres. A primeira constatação importante deve assim destacar o caráter feminizado das relações de confidência. De acordo com os nossos dados, corrobora-se a idéia, bem explicitada por Giddens (1996), de que a reflexividade sobre a intimidade é uma qualidade historicamente desenvolvida sobretudo entre as mulheres, por oposição ao estereotípico afastamento masculino de um mundo de afetos, tendencialmente conotado com o feminino.

A análise do perfil de gênero da rede de confidentes segundo o sexo dos inquiridos acrescenta informações interessantes: apenas 55,6\% dos homens têm como confidentes outros homens; pelo contrário, as lógicas intra-gênero aplicam-se a quase $80 \%$ das mulheres. Entre os homens são mais freqüentes as redes de confidência mistas $(23,5 \%)$ ou apenas femininas (20,9\%), tendência que contrasta claramente com o perfil das redes femininas, quase sempre apoiadas na partilha da intimidade entre mulheres (Wall e col., 2001). Uma das razões subjacentes a esta diferença de gênero poderá residir precisamente nas particularidades constitutivas da feminilidade e da masculinidade. Se às mulheres se associa idealmente o mundo dos afetos por contraste com a maior sexualização da masculinidade, muitos homens poderão encontrar espaço para a partilha da intimidade afetiva junto de mulheres, pessoas fora do jogo simbólico da competição sexual masculina (Pleck, 1993). Afinal, a confidência de questões e problemas sexuais e amorosos implica a exposição de si face ao outro, podendo gerar, no seio da masculinidade dominante, o receio de parecer fraco ou efeminado perante os pares (Connell, 1995). O fechamento feminino das mulheres comporta, por outro lado, uma orientação de gênero homóloga, pautada pela restrição do mundo íntimo e da sexualidade a esse universo.
Do ponto de vista da proximidade etária entre confidentes e inquiridos, a tendência majoritária é para que as relações de intimidade sejam desenvolvidas no interior dos mesmos intervalos etários (52\% da amostra). Dentre a outra metade, cerca de um quinto identifica confidentes de intervalos etários mais jovens, $17,6 \%$ nomeia pessoas de diferentes idades e apenas $11,4 \%$ declara falar de sexo com indivíduos mais velhos.

Finalmente, analisamos as redes de confidência a partir da percepção que os inquiridos têm acerca do comportamento sexual dos seus confidentes. Utilizamos, para o efeito, duas questões-chave: a percepção sobre o número de parceiros sexuais dos confidentes ao longo do último ano e a percepções sobre as estratégias de prevenção utilizadas pelos confidentes face aos riscos de transmissão do HIV/ aids. Perguntava-se aos inquiridos quantos parceiros sexuais pensavam que os seus confidentes tiveram no último ano e se achavam que estes eram seletivos na seleção desses parceiros devido ao receio da infecção HIV/aids (tabela 1).

Relativamente à percepção sobre o número de parceiros dos confidentes, optamos por isolar as respostas que identificaram confidentes multiparceiros, ou seja, que tiveram vários parceiros sexuais no último ano (vários parceiros diferentes ou um parceiro regular e outros ocasionais), diferenciando-as dos confidentes com apenas um parceiro. Globalmente, verificamos que entre os homens entrevistados, quase metade pensa que os seus confidentes tiveram vários parceiros sexuais ao longo do último ano; entre as mulheres, esta percentagem desce, abrangendo apenas cerca de $20 \%$ dos casos. A visão masculina dos confidentes é, como esperávamos, mais permissiva do que a das mulheres. No entanto, apesar desta diferença significativa ao nível do número de parceiros, no respeitante à percepção sobre as formas de seleção de parceiros sexuais utilizadas pelos confidentes, percentagens não muito diferentes de homens $(70,5 \%)$ e de mulheres $(62,6 \%)$ pensam que os seus confidentes têm particular atenção em selecionar os parceiros sexuais devido ao receio de ser infectado com o HIV/aids.

Por fim, a última dimensão de caracterização da rede indagava sobre as relações sexuais entre 
inquiridos e confidentes, sendo que nenhum dos confidentes, como foi explicitado anteriormente, era o cônjuge da pessoa entrevistada. Na maioria dos casos, nunca houve relacionamentos sexuais entre ambos. No entanto, em 10,4\% das situações é descrita a ocorrência de relações sexuais entre os inquiridos e os seus confidentes. Esta prática está, por conseguinte, longe de ser a lógica da maioria, assim indicando a independência entre atividade sexual e diálogo sobre sexualidade. Observam-se, todavia, diferenças de gênero significativas que importa assinalar. São, afinal, os homens quem mais declara ter tido este tipo de relação com os confidentes: enquanto $15,5 \%$ destes referem ter tido relações sexuais, apenas $5,8 \%$ das mulheres o fazem, quase três vezes menos, portanto.

\section{Comportamento Sexual: número de parceiros $e$ relações ocasionais}

As diferenças de gênero são, aliás, muito evidentes ao nível do comportmento sexual dos indivíduos (tabela 2). Efetivamente, nos vários indicadores por nós analisados, as diferenças de gênero são, desde logo, flagrantes, assim reiterando os resultados de vários outros inquéritos à sexualidade realizados em vários países:veja-se , por exemplo, Laumann e col., 1994, para os E.U.A.; Bajos e col., 2007, para a França; Wellings e col., 1994, para a Grã-Bretanha; ou Ministério da Saúde, 200o, para o Brasil, entre outros.

De forma geral, encontramos na amostra percentagens mais significativas de homens cujos últimos parceiros foram relações ocasionais - 15,7\% e 21,8\% dos homens referem que o último e o penúltimo parceiro, respectivamente, foram ocasionais, contra $4,5 \%$ e 5,9\% das mulheres. Em relação ao uso de preservativo nessas relações ocasionais, as diferenças permanecem: $6,5 \%$ dos inquiridos da amostra não usaram preservativo nas relações ocasionais que tiveram com o último ou penúltimo parceiro. Porém, enquanto esta ausência de prevenção abrange cerca de $10 \%$ dos homens, apenas se aplica a 2,7\% das mulheres. 0 número de parceiros sexuais declarados pelos homens - quer ao longo da vida, quer nos últimos cinco anos - é também, e como seria de esperar, bastante mais expressivo do que os declarados pelas mulheres.

Tabela 2 - Distribuição da proporção (\%) de pessoas segundo sexo e variáveis dependentes de comportamento sexual. Adultos em Portugal, $2007(n=3335)$

\begin{tabular}{|c|c|c|c|}
\hline & Total & Homens & Mulheres \\
\hline \multicolumn{4}{|l|}{ Número de parceiros sexuais ao longo da vida (\%) } \\
\hline Um parceiro & 36,6 & 18,2 & 55,7 \\
\hline Dois parceiros & 14,2 & 12,4 & 16,0 \\
\hline Três parceiros & 10,3 & 10,2 & 10,4 \\
\hline Quatro ou mais & 38,9 & 59,1 & 17,8 \\
\hline Total & 100,0 & 100,0 & 100,0 \\
\hline \multicolumn{4}{|l|}{ Número de parceiros nos últimos cinco anos (\%) } \\
\hline Nenhum parceiro & 13,5 & 15,6 & 11,4 \\
\hline Um parceiro & 59,9 & 49,7 & 70,5 \\
\hline Dois parceiros & 7,9 & 7,3 & 8,5 \\
\hline Três parceiros & 5,6 & 6,5 & 4,6 \\
\hline Quatro ou mais & 13,1 & 20,9 & 5,0 \\
\hline Total & 100,0 & 100,0 & 100,0 \\
\hline \multicolumn{4}{|l|}{ Últimos dois parceiros e relações ocasionais } \\
\hline Último parceiro relação ocasional (\% na amostra) & 10,6 & 15,7 & 4,5 \\
\hline Penúltimo parceiro relação ocasional (\% na amostra) & 14,0 & 21,8 & 5,9 \\
\hline Ultimo ou penúltimo parceiro, relação ocasional sem usar preservativo (\% na amostra) & 6,5 & 10,2 & 2,7 \\
\hline
\end{tabular}


Na próxima e última secção deste artigo completamos a análise, procurando testar a nossa hipótese do impacto da rede nos comportamentos sexuais dos indivíduos. 0 recurso a técnicas estatísticas de regressão permite-nos observar as interações complexas de causalidade existentes entre o conjunto de variáveis que identificamos no modelo de análise. Através destes procedimentos estatísticos conseguimos avaliar o impacto global dessas mesmas variáveis no seu conjunto. Só assim podemos comprovar que o "efeito de rede" não é apenas um espelho de outras diferenças fundadas, por exemplo, na geração, no gênero, nos capitais acadêmicos ou na situação conjugal.

\section{Redes sociais e comportamento sexual}

Em face deste objetivo, construímos um modelo de regressão congregando todas as variáveis sóciodemográficas utilizadas, às quais acrescentamos ainda a freqüência da atividade religiosa, e todas as variáveis de rede descritas ao longo do capítulo: a rede normativa de amigos e de familiares, o número de confidentes, o sexo e a idade desses confidentes, os indicadores de comportamento sexual dos confidentes (percepções sobre o numero de parceiros ao longo do último ano e estratégias de seleção de parceiros sexuais) e, finalmente, as relações sexuais existentes entre os inquiridos e os seus confidentes. Testamos este modelo de regressão sobre três variáveis dependentes: o número de parceiros sexuais nos últimos 5 anos, as relações sexuais com parceiros ocasionais (últimos dois parceiros), e as relações sexuais com parceiros ocasionais em que não se usou preservativo. A escolha destes indicadores de comportamento sexual obedeceu aos objetivos inicialmente explicitados de procurar aferir qual o impacto efetivo das redes sociais sobre práticas que podem ser consideradas de risco. Referimo-nos nomeadamente à ausência de prevenção em relações sexuais esporádicas levadas a cabo com pessoas conhecidas e até com desconhecidas.

Comecemos, no entanto, por observar os resultados da regressão linear efetuada sobre o número de parceiros sexuais nos últimos 5 anos (tabela 3 ). Tal como para as outras variáveis dependentes, realizamos três análises de regressão: uma para o total da população e as outras duas em separado para os homens e para as mulheres. Em face das lógicas de gênero atuantes neste campo da vida privada, pretendíamos descobrir eventuais especificidades inerentes às experiências sexuais e sociais no masculino e no feminino.

$\mathrm{Na}$ verdade, no procedimento efetuado para o conjunto da população inquirida, podemos verificar que a variável sexo é particularmente importante enquanto preditora do número de parceiros. Relativamente às restantes variáveis sócio-demográficas o peso que assumem nos modelos de regressão depende, de fato, do sexo dos inquiridos. Globalmente, as coordenadas etárias e escolares são mais importantes para prever o número de parceiros sexuais das mulheres, ao passo que a situação conjugal assume particular relevo no caso dos homens. Mulheres mais novas e mais escolarizadas tenderão a ter mais parceiros. Entre os homens, estar dentro ou fora da vida em casal pode ser determinante para equacionar este comportamento.

Porém, os resultados mais interessantes, do ponto de vista da hipótese que procuramos testar, são os que se prendem com os efeitos de rede revelados pela análise de regressão. 0 número de parceiros sexuais, tanto de homens como de mulheres, parece poder ser predito, em certa medida, pelo comportamento sexual dos confidentes sexuais. Não obstante cerca de metade dos inquiridos na amostra ter declarado não ter confidentes, esta relação mostra a importância destes últimos como fatores de influência do comportamento sexual individual. Na verdade, os resultados do estudo mostraram que quem declarou ter confidentes sexuais tende a ter mais parceiros sexuais. A tendência acima observada é, aliás, similar para homens e para mulheres, não obstante os resultados diferirem consoante o sexo. O comportamento sexual atribuído aos confidentes parece assim constituir um preditor relevante com influência sobre o número de parceiros sexuais nos últimos 5 anos, confirmando-se portanto a pertinência da nossa hipótese inicial sobre a homologia comportamental entre inquiridos e confidentes. Em face dos resultados expostos, parece, de fato, estabelecer-se uma conexão estatística entre o número de parceiros sexuais dos indivíduos e a sua rede de confidentes. Além disso, existe também um certo efeito preditor da rede normativa sobre $o$ 
Tabela 3 - Comportamento sexual e preditores sócio-demográficos e de rede Regressões lineares (Coeficientes estandardizados - Beta)

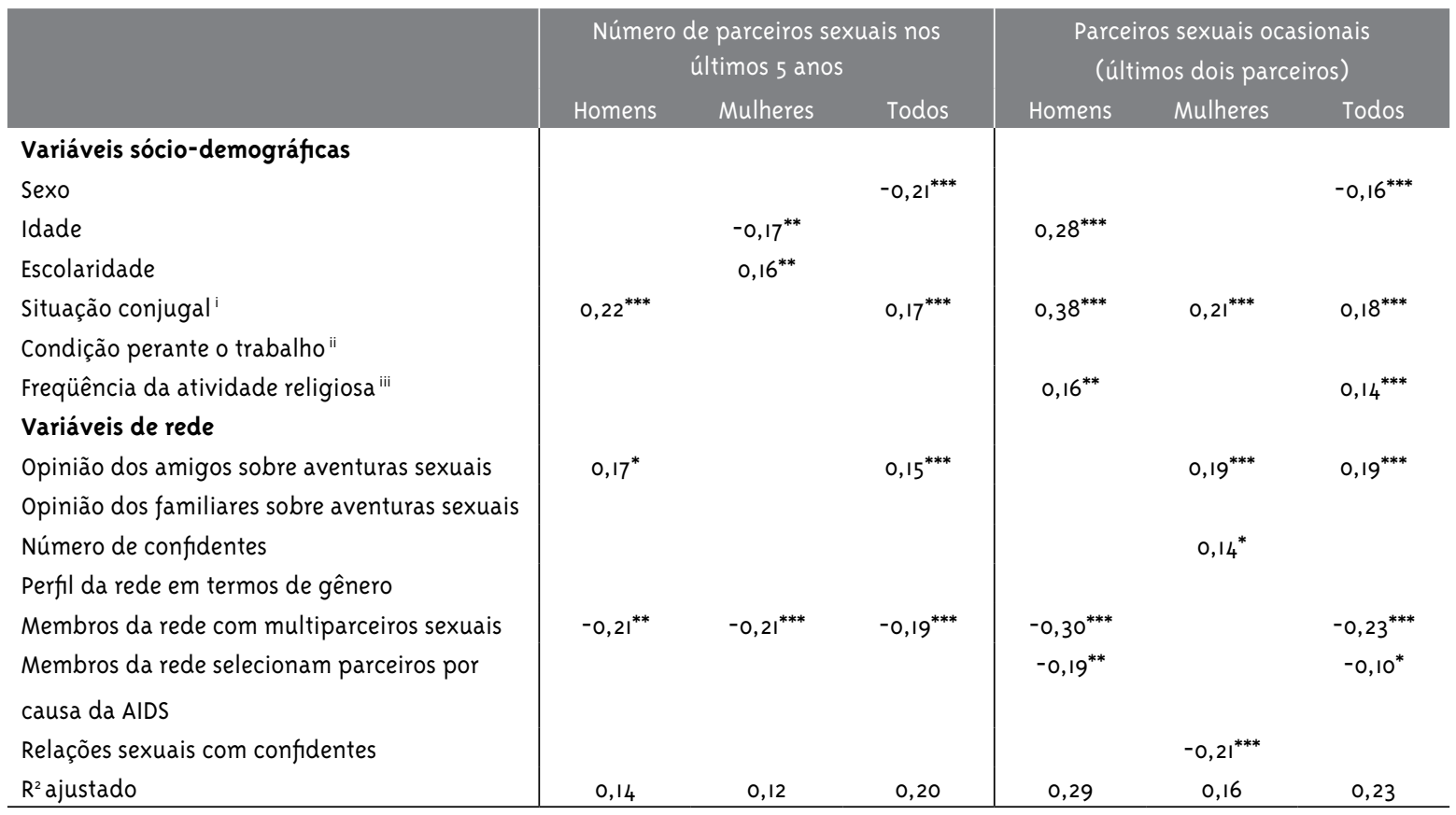

Nota: Os valores são coeficientes de regressão estandardizados (betas) estatisticamente significativos: ${ }^{*} p<0,0$; ${ }^{* *} p<0,05 ;{ }^{* * *} p<0,00$. As células vazias correspondem a coeficientes de regressão estandardizados estatisticamente não significativos ( $p>0,0$ ). Os códigos das variáveis utilizadas são os seguintes: ${ }^{i}$ I)casamento; 2) coabitação; 3)solteiro com relacionamento; 4 )solteiro sem relacionamento. ii I)trabalha; 2 )não trabalha. iii 1 )todos os dias a 8 )nunca.

número de parceiros. Porém, enquanto os homens parecem ser mais influenciados pela opinião dos amigos acerca das aventuras sexuais, esta variável normativa parece ser pouco relevante como preditora do número de parceiros sexuais das mulheres nos últimos 5 anos.

Vejamos os resultados da segunda regressão linear (tabela 3). Relativamente à segunda variável dependente em análise (o ter tido parceiros sexuais ocasionais), o modelo explicativo é particularmente eficaz para prever este comportamento sexual no grupo masculino (Clark, 1990), por comparação com o grupo feminino, ao qual a adequação do modelo de regressão é menor, como mostram as diferenças verificadas na abrangência explicativa global dos modelos (enquanto no caso dos homens temos um $\mathrm{R}^{2}$ de o,29, entre as mulheres este valor situa-se nos $0,16)$. No entanto, em ambos os casos se verifica um efeito preditor das variáveis de rede, embora pesem as diferenças de gênero reveladas nos procedimentos de regressão. No caso dos homens, as coordenadas mais importantes são as que se referem ao comportamento sexual dos confidentes: se os inquiridos acham que os seus confidentes tiveram vários parceiros no último ano, é mais provável que eles próprios tenham tido também mais relações sexuais ocasionais (coeficiente de o,3o). Além desta variável, tem ainda impacto a que se refere às estratégias preventivas dos confidentes: confidentes que selecionam os seus parceiros sexuais em função do receio do HIV/aids associam-se a homens com maiores probabilidades de terem tido parceiros sexuais ocasionais. Relativamente às mulheres, a rede é, como notamos, igualmente importante, embora os parceiros ocasionais declarados pelas mulheres se associem a outro conjunto de variáveis. As mulheres são mais sensíveis a coordenadas normativas como a opinião que os amigos têm sobre aventuras sexuais, ao número de confidentes sexuais e ao próprio fato de terem tido um envolvimento sexual com pelo menos um desses confidentes. Para elas, os aspetos de pressão reguladora decorrentes da rede normativa 
parecem, assim, ter mais relevância no que respeita a este tipo de comportamento sexual. Amigos mais liberais são importantes para legitimar práticas sexuais ocasionais.

Finalmente, a terceira análise de regressão (agora uma regressão logística dada a natureza binária da variável dependente: usou/não usou preservativo com os parceiros sexuais ocasionais) permite-nos testar a adequação do modelo explicativo a práticas sexuais de "risco" (tabela 4). Além da idade, importante quer para homens quer para mulheres, e da escolaridade, mais relevante no caso dos primeiros, as variáveis de rede surgem novamente como elementos preditores deste comportamento sexual, sobretudo no caso das mulheres. Para elas, o modelo de regressão revelou maior adequação (o pseudo $\mathrm{R}^{2}$ é de o,48, bastante elevado, portanto), destacandose o impacto da dimensão normativa da rede social - a opinião dos amigos, a opinião dos familiares. Redes de relacionamento social mais permissivas relativamente à infidelidade e às aventuras sexuais associam-se a comportamentos mais liberais e também de maior risco, em face de uma eventual infecção por DSTs. No caso dos homens, o uso de preservativo parece associar-se, sobretudo, a idades mais jovens e a escolaridades mais elevadas.

Em suma, os procedimentos de regressão ajudaram-nos a captar o efeito conjunto das variáveis que selecionamos e assim comprovar o efeito da rede sobre o comportamento sexual dos inquiridos. Em linhas gerais, a similitude entre comportamentos sexuais de inquiridos e de confidentes parece revestir-se de alguma importância para equacionar a diversidade de experiências sexuais. De relevo são igualmente os ambientes normativos que caracterizam as redes de relacionamento social dos inquiridos. Tanto a rede de confidentes como a rede normativa produzem efeitos específicos que, segundo os dados, têm influência nos comportamentos sexuais de homens e de mulheres.

\section{Tabela 4 - Relações sexuais com parceiros ocasionais sem usar preservativo (últimos dois parceiros) e preditores sócio-demográficos e de rede. Regressões logísticas (coeficientes de regressão)}

\begin{tabular}{|c|c|c|c|}
\hline & Homens $(n=158)$ & Mulheres $(n=204)$ & Todos $(n=362)$ \\
\hline \multicolumn{4}{|l|}{ Variáveis sócio-demográficas } \\
\hline Sexo & & & $1,10^{* *}(4,34)$ \\
\hline Idade & $-0,07^{* * *}(8,84)$ & $-0,08^{* *}(4,36)$ & $-0,11^{* * *}(22,56)$ \\
\hline Escolaridade & $-0,39^{* *}(4,47)$ & & $-0,44^{* * *}(8,29)$ \\
\hline \multicolumn{4}{|l|}{ Situação conjugal } \\
\hline \multicolumn{4}{|l|}{ Condição perante o trabalho } \\
\hline \multicolumn{4}{|l|}{ Freqüência da atividade religiosa } \\
\hline \multicolumn{4}{|l|}{ Variáveis de rede } \\
\hline Opinião dos amigos sobre aventuras sexuais & & $-1,83^{* * *}(8,96)$ & $-0,60^{* *}(6,05)$ \\
\hline \multicolumn{4}{|l|}{ Opinião dos familiares sobre aventuras sexuais } \\
\hline Número de confidentes & & $-0,74^{* * *}(10,87)$ & \\
\hline Perfil da rede em termos de gênero & & & $-0,94^{* * *}(8,38)$ \\
\hline \multicolumn{4}{|l|}{ Perfil da rede em termos etários } \\
\hline Membros da rede com multiparceiros sexuais & & & $1,03^{*}(3,66)$ \\
\hline \multicolumn{4}{|c|}{ Membros da rede selecionam parceiros por causa da AIDS } \\
\hline \multicolumn{4}{|l|}{ Relações sexuais com confidentes } \\
\hline Nagelkerke $\mathrm{R}^{2}$ & 0,17 & 0,48 & 0,31 \\
\hline
\end{tabular}

Nota: Os valores são coeficientes de regressão estandardizados estatisticamente significativos: ${ }^{*} p<0,0 \mathrm{o} ;{ }^{* *} p<0,05 ;{ }^{* * *} p<0,00 \mathrm{l}$. As células vazias correspondem a coeficientes de regressão estandardizados estatisticamente não significativos $(p>0,01)$. 


\section{Discussão e Conclusões}

Para terminar, importa rever e discutir algumas das principais conclusões reveladas pela análise efetuada. Em primeiro lugar, pretendíamos aferir qual o impacto dos constrangimentos normativos vividos no seio das redes de relações com familiares e com amigos sobre o comportamento sexual dos indivíduos. Em segundo lugar, procuramos observar o impacto gerado pela rede prática de confidentes, verificando até que ponto o perfil destes últimos estabelece conexões explicativas com o comportamento sexual de homens e de mulheres. Evidentemente, não obstante os resultados apontarem para uma relação pertinente entre ambas as dimensões - a rede e o comportamento sexual -, a abrangência das conclusões retiradas não deixa de ser afetada por algumas limitações inerentes à pesquisa quantitativa efetuada em Portugal. Gostariamos de salientar dois aspetos importantes. O primeiro incide sobre a forma como foi operacionalizada a rede social, aqui limitada a aspetos normativos e de confidência sexual, seguindo os procedimentos sugeridos por Ferrand e Mounier $(1993,1998)$. Muito embora estas duas dimensões se tenham revelado relevantes e apontem para resultados semelhantes aos encontrados, na França, pelos autores referidos, será, sem dúvida, útil que em futuras pesquisas se incluam na análise outras dimensões de rede. 0 presente estudo analisa, afinal, apenas dois aspectos da rede, dentre muitos outros que poderiam revelarse importantes numa perspectiva epidemiológica. As formas de selecção de parceiros sexuais, entre outras dimensões das redes sociais, constituem um fator de grande importância que não foi contemplado na nossa pesquisa (a este respeito ver, por exempo, Morris 1997; Heckathorn e col., 1999, entre outros). 0 segundo problema, claramente decorrente da perspectiva de rede de confidência sexual que utilizamos, repousa no fato de cerca de metade dos respondentes ter declarado não ter quaisquer confidentes e de cerca de um quinto ter indicado apenas um confidente. Certamente, a inclusão de outras medidas de rede, em consonância com uma análise de redes mais multi-dimensional (Scott 200o, entre outros), como sugerimos acima, poderia evidenciar mais claramente a importância das variáveis de rede para a compreensão do comportamento sexual, do risco e da prevenção face às DSTs e ao HIV/aids. Porém, os resultados apresentados permitem, apesar das limitações apontadas, destacar a prevalência de um "efeito de rede", que deve ser considerado quer na descrição dos comportamentos sexuais, quer nas práticas preventivas face ao risco de infecção por DSTs, como salientam, aliás, diversos autores (Bell e col., 1998; Bell e col., 2002).

Assim, relativamente à dimensão normativa da rede social, observamos algumas tendências importantes. Em primeiro lugar, importa relembrar as diferenças entre as redes de familiares e as de amigos, pois as primeiras são geralmente muito mais conservadoras do que as segundas, no respeitante à percepção que delas têm os inquiridos. A infidelidade e a aventura amorosa-sexual constituem comportamentos muito mais censurados no seio da família e muito mais tolerados no universo dos amigos. Seguindo de perto os resultados obtidos por Ferrand e Mounier (1998) a partir dos dados do inquérito francês à sexualidade de 1992, constatamos serem raras as redes normativas em que todos os familiares e todos os amigos são permissivos. No entanto, a tendência majoritária traça um retrato normativo heterogêneo em que os amigos são mais liberais do que os familiares em matéria de moral sexual.

Em segundo lugar, em consonância com a idéia inicial, é de assinalar a importância dos amigos na configuração das relações sociais dos inquiridos, sobretudo quando nos reportamos aos homens. Face ao ideal monogâmico imperante no seio familiar, que restringiu, a favor da transparência afetiva, o tradicional duplo padrão de gênero pautado por normas diferentes relativamente à infidelidade masculina, mais aceitável nas famílias tradicionais, e à feminina, sempre interdita e censurada, os amigos fornecem o ambiente de tolerância sexual capaz de legitimar a infidelidade conjugal. A existência de redes sociais não conservadoras para lá do universo familiar, tendência mais expressiva no grupo masculino, parece assim articular-se significativamente às biografias sexuais dos indivíduos, permitindo-lhes um controlo mais individualizado da sua própria sexualidade. Esta tendência é importante para homens e para mulheres, embora pese o maior impacto 
regulador da rede normativa sobre o comportamento sexual das mulheres, como mostraram os resultados obtidos através das análises de regressão. Como tem sido largamente argumentado (Irvine 1990), , a permanência de normas de gênero (partilhadas no seio da rede) mais restritivas da liberdade sexual das mulheres tem um impacto profundo sobre a vivência feminina da sexualidade. Pelo contrário, normatividades mais liberais e hedonistas continuam a fazer parte da codificação da sexualidade masculina e, em grande medida, a reproduzir um modelo de duplopadrão de gênero no respeitante à sexualidade, como notou igualmente Campbell (1995), ao analisar a realidade norte-americana. Apesar das grandes mudanças que têm vindo a transformar as relações de gênero e os comportamentos sexuais femininos (Bozon, 2005), a diferenciação de gênero continua a pesar sobre os comportamentos e as normas da sexualidade. A maior incidência de sexo com parceiros ocasionais (usando ou não o preservativo) entre a população masculina constitui, desde logo e entre outras, uma evidência clara da permanência de desigualdades de comportamento sexual, como demonstrou também Clark (1990).

Porém, como seria de esperar, a configuração da rede normativa segue linhas de mudança geracional acentuadas, quer no caso das mulheres, quer no dos homens. Globalmente, gerações mais jovens e indivíduos mais escolarizados tendem a descrever redes heterogêneas e a sublinhar a diferença entre as redes de familiares e os de amigos, lembrando a atualidade da tese de Giddens (1996) sobre as transformações da intimidade na modernidade avançada. Beneficiam assim de sociabilidades plurais e eventualmente favoráveis a uma maior liberdade individual no campo da sexualidade, em concordância com a tese proposta por Shorter (1995) sobre o enfraquecimento do papel regulador da família e do parentesco. Em suma, acentua-se a diferença entre redes conservadoras e de base familiar e redes mais liberais onde os amigos são fundamentais. As primeiras associam-se a comportamentos mais restritivos da experiência sexual e as segundas a práticas mais plurais em matéria de sexualidade, como também demonstraram Ferrand e Mounier $(1993,1998)$.

Estes contrastes evidenciam-se igualmente ao nível das redes de confidência, confirmando o papel mais restritivo que se associa à família por contraste com a maior permissividade dos amigos. A verdade é que, na maioria dos casos, sobretudo em gerações mais jovens, em grupos mais escolarizados e entre os homens, os confidentes nomeados fazem parte do universo dos amigos. Mais uma vez, a maior inclusão de uma significativa parte das mulheres em redes de confidência constituídas por familiares e por outras mulheres reproduz uma diferença de gênero, cujo impacto ao nível do comportamento sexual deve ser salientado. Embora cerca de metade dos inquiridos não tenha identificado qualquer confidente, esta tendência é, ainda assim, bastante relevante. A rede de confidentes é normalmente restrita - lembremos que cerca de um quinto dos homens e das mulheres fala da sua vida sexual apenas com uma pessoa, 13-14\% fá-lo com duas pessoas e somente cerca de $13 \%$ diz ter três ou mais confidentes. Porém, falar de sexo com outras pessoas constitui um elemento particularmente relevante para a compreensão dos comportamentos sexuais dos indivíduos, sejam homens ou mulheres. Ter confidentes marca, desde logo, uma atitude e uma prática mais liberal em matéria de sexualidade, demonstrando a importância da reflexividade partilhada nos processos de erotização e libertação sexual dos sujeitos. Deste ponto de vista, a conexão entre o perfil da rede de confidentes e o comportamento sexual dos inquiridos corrobora a nossa idéia inicial, demonstrando a importância de abordar a sexualidade e os comportamentos de risco e prevenção numa perspectiva de rede, que contemple as relações sociais dos indvíduos e a forma como se influenciam reciprocamente.

Algumas coordenadas revelaram-se particularmente importantes: ter redes mistas do ponto de vista do sexo e heterogêneas do ponto de vista etário parece promover comportamentos sexuais mais descomprometidos e maior diversidade de parceiros sexuais. Estes resultados encaixam-se sem grande dificuldade no pressuposto de que a pertença a universos plurais e libertos das amarras do parentesco ou de um denso inter-conhecimento entre os membros das várias redes sociais tenderá a promover a individualização do sujeito, bem como morais sexuais mais liberais. Mais interessante ainda é a já referida homologia relativa entre comportamento sexual dos inquiridos e dos seus confidentes. A par 
de coordenadas sociais, como a geração, o gênero ou a escolaridade, a rede social tem afinal um impacto relevante. Confidentes a quem se atribuem maior número de parceiros sexuais ou particular cuidado com a prevenção de DSTs são nomeados por indivíduos com comportamentos semelhantes. Tanto numa perspectiva relacional da sexualidade como numa óptica epidemiológica, a observação das redes de relações sociais dos indivíduos constitui assim, como foi sugerido por Heckathorn e colaboradores (1999) - entre vários outros autores -, um aspecto importante para a compreensão e explicação da variedade de experiências sexuais, mais restritas ou mais plurais, e para os riscos de infecção que daí podem advir.

\section{Referências}

ARIÈS, P. L'enfant et la vie familiale sous l'Ancien Regime. Paris: Seuil, 1973.

BAJOS, N. et al. La sexualité aux temps du Sida. Paris: PUF, 1998.

BAJOS, N.; MARQUET, J. Research on HIV sexual risk: social relations-based approach in a crosscultural perspective. Social Science \& Medicine, Oxford, v. 5o, n. 11, p. 1533-1546, jul. 2000.

BAJOS, N.; BOZON, M.; BELTZER, N. Contexte de la sexualité en France. Paris: INSERM, ANRS, INED, 2007.

BARCELLOS, C.; BASTOS, F. I. Redes sociais e difusão da AIDS no Brasil. Boletín de la Oficina Sanitaria Panamericama, PAHO, Washington, v. 121, n. 1, p. 11-24, jul. 1996.

BECK, U.; BECK-GERNSHEIM, E.

Individualization: institutionalized individualism and its social and political consequences. Londres: Sage, 2002.

BEHRMAN, J. R.; KOHLER, H.P.; WATKINS, S. C. Social Networks, HIV/AIDS and risk perceptions. Demography, Washington, v. 44, n. 1, p. 1-33, feb. 2007. Disponível em: <http://repository.upenn.edu/ cgi/viewcontent.cgi?article=10oo \&context=parc pubs>. Acesso em: 14 fev. 2007.
BELL, D. C.et al. Social network utility and the economics of risk: the case of HIV. Journal of Economic Behavior and Organization, Knoxville, TN, v. 33, n. 2, p. 195-205, jan. 1998.

BELL, D. C. et al. Social networks and forecasting the spread of HIV infection. Jaids: Journal of Acquired Immune Deficiency Syndromes, Philadelphia, P.A., v. 31, n. 2, p. 218-229, out. 2002.

BOZON, M. Sociologie de la sexualité. Paris: Armand Colin, 2005.

BRASIL, Ministério da Saúde. Comportamento sexual da população brasileira e percepções do HIV/AIDS. Brasília: Série Avaliação, 2000.

CABRAL, M. V.et al. Saúde e Sexualidade em Portugal: resultados preliminares. Lisboa: ICS, 2008.

CAMPBELL, C. A. Male gender roles and sexuality: implications for women's AIDS risk and prevention. Social Science \& Medicine, Oxford, v. 41, n. 2, p. 197-210, jul. 1995.

CLARK, R. D. The Impact of AIDS on gender differences in willingness to engage in casual sex. Journal of Applied Social Psychology, Malden, M.A., v. 20, n. 9, p. 771-782, maio 1990.

CONNELL, R.W. Masculinities. Cambridge: Polity Press, 1995.

ELIAS, N. A Sociedade dos indivíduos. Lisboa: Dom Quixote, 1993.

ERICKSON, B. H. The relational basis of attitudes. In: WELLMAN, B.; BERKOWITZ, S. D. Social structures: a network approach. New York: Cambridge University Press, 1988. p. 112-135.

FERRAND, A.; MOUNIER, L. L'échange de paroles sur la sexualité: une analyse des relations de confidence. Population, Paris, n. 5, p. 1451-1475, set./out. 1993 .

FERRAND, A.; SNIJDERS, T. A. B. Social networks and normative tensions. In: VAN CAMPENHOUDT, L. et al. Sexual Interactions and HIV risk: new conceptual perspectives in European Research. Londres: Taylor \& Francis, 1997. p. 6-21. 
FERRAND, A.; MOUNIER, L. Influence des réseaux de confidence sur les relations sexuelles. In: BAJOS, N. et al. La sexualité aux temps du Sida. Paris: PUF, 1998. p. 255-304.

FESTINGER, L. A theory of social comparison processes. Human Relations, New York, N.Y., v. 7, n. 2, p. 117-140, maio 1954.

FLANDRIN, J.-L. Le Sexe et l'Occident : evolution des attitudes et des comportements. Seuil: Paris, 1981.

FOUCAULT, M. Histoire de la sexualité: la volonté de savoir. Paris: Gallimard, 1976. v. 1.

FOWLER, J. H.; CHRISTAKIS, N. A. Estimating peer effects on health in social networks. Journal of Health Economics, Amsterdã, v. 27, n. 5, p. 140o1405 , set. 2008.

GIDDENS, A. As transformações da intimidade: sexualidade, amor e erotismo nas sociedades modernas. Oeiras: Celta, 1996.

GOETHE, W. As afinidades eletivas. São Paulo: Nova Alexandria, 2008 [1809].

HECKATHORN, D. D. Collective sanctions and compliance norms: a formal theory of GroupMediated Social-Control. American Sociological Review, Nashville, TN, v. 55, n. 3, p. 366-384, jun. 1990.

HECKATHORN, D. D. et al. Aids and social networks: HIV prevention through network mobilization. Sociological Focus, Cincinnati, OH, . V. 32, n. 2, p. 159-177, maio 1999.

IRVINE, J. M. From difference to sameness: gender ideology in sexual science. The Journal of sex research, Uxbridge, v. 27, n. 1, p. 7-24, fev. 1990.

LAUMANN, E. O. et al. The social organization of sexuality: sexual practices in United States. Chicago, Londres: University of Chicago Press, 1994 .

LEVY, J. A.; PESCOSOLIDO, B. A. Social networks and health (Advances in Medical Sociology).

Greenwich: JAI Press, 2002.

LILJEROS, F.; EDLING, C. R.; AMARAL, L.

A. N. Sexual networks: implications for the transmission of sexually transmitted infections. Microbes and Infection, Paris, v. 5, n. 2, p. 189-196, fev. 2003.
LUHMANN, N. O Amor como paixão: para a codificação da intimidade. Lisboa: Difel, 1991.

MORRIS, M. Sexual networks and HIV. AIDS, Philadelphia, P.A., v. 11 (suppl. A), p. 209-216, fev. 1997.

MOSHER, W. D.; CHANDRA, A.; JONES, J. Sexual behaviour and selected health measures: men and women 15-44 years of age, United States, 2002, Advanced Data, Rockville, M.d., v. 15, n. 362, p. 1-55, sep. 2005.

PARSONS, T.; BALES, R. Family, socialization and interaction process. New York: Free Press, 1955.

PLECK, J. H.; SONENSTEIN, F. L.; KU, L. C. Masculinity ideology: Its impact on adolescent males' heterosexual relationships. Journal of Social Issues, Malden, M.A., v. 49, n. 3, p. 11-29, fall. 1993 .

PUTNAM, R. Bowling alone: America's declining social capital. Journal of Democracy, Washington D.C., v. 6, n. 1, p. 65-78, jan. 1995.

SCOTT, J. Social network analysis. London: Sage, 2000.

SENNETT, R. Les tyrannies de l'intimité. Paris: Éditions du Seuil, 1974.

SHORTER, E. A Formação da Família Moderna. Lisboa: Terramar, 1995.

SMITH, K. P.; CHRISTAKIS, N. A. Social networks and health. Annual Review of Sociology, Massachusetts, C.A., v. 34, p. 405-429, ago. 2008.

UNAIDS, Report on the global AIDS epidemic. Genebra: UNAIDS, 2008.

WALL, K. et al. Families and informal support networks in Portugal: the reproduction of inequality. Journal of European Social Policy, Londres, v. 11, n. 3, p. 213-233, ago. 2001.

WELLINGS, K. et al. Sexual behaviour in Britain. Londres: Penguin, 1994.

Recebido em: 20/01/2010

Reapresentado em: 31/07/2010

Aprovado em: 03/08/2010 